\title{
Innovation Design of Engineering Experiment Based on Internet
}

\author{
Zhang Bingsheng ${ }^{1, a}$, Zhu Qingjie ${ }^{1, b}$ and Li Xue $e^{1, c}$ \\ ${ }^{1}$ School of petroleum engineering, Changzhou University, Changzhou 213016, China \\ azbs@cczu.edu.cn, ${ }^{\mathrm{b}}$ qjzhu@cczu.edu.cn, ${ }^{9}$ lix@cczu.edu.cn
}

Keywords: Innovation design; Engineering experiment; Education technology; Internet; QR Code. Abstract. As the progress of innovation design for open experiment in engineering education, it is necessary to investigate the design method based on internet. Through structure analyzing of Browser/Server model, the real time evaluating method in server and system application development are investigated with JavaScript and VBScript as Active Server Page (ASP). As an example of petroleum engineering safety evaluation, MapXtreme resolution and QR code sharing methods for innovation experiment design is discussed. System application and internet sharing of comparison matrix input and experiment evaluation results browse is developed. Finally, the experiment results are analyzed and some advice is proposed.

\section{Introduction}

As the progress of web technology, it has been a helpful tool for innovation design of open engineering experiment. Especially, the QR code that is an effective data matrix of two-dimensional code symbol, which was developed by Denso Company, has been made a quickly applied in engineering education based on internet $t^{[1,2]}$. Therefore, services for any users in the world become very convenient through Internet. Meanwhile, web-based services, such as spatial surface analysis, decision making, risk analysis, can be integrated with web. GIS analysis, such as multi criteria evaluation(MCE), can be applied in many fields. The application of integrated information technology has been changed the manner of engineering education, such as open online courses ${ }^{[3-5]}$. And online remote engineering experiment design will be another technology innovation in engineering education.

As a relatively new method, GIS-based multi criteria evaluation (MCE) has been applied in many field of engineering safety evaluation, such as casing failure analysis in petroleum engineering, land-use suitability evaluation in city planning, risk assessment of disaster ${ }^{[6,7]}$. There are two types MCE that are including in GIS, Boolean overlay and weighted linear combination(WLC $)^{[8,9]}$. Because of the needs of many engineering problems for integrated evaluation, this method has broad application prospects ${ }^{\text {[10-12] }}$. Therefore, an innovation experiment design in safety evaluation is discussed in this paper, and this will be a resolution for complicate engineering experiment.

\section{System Structure Design as Basis of Internet}

A Browser/Server system structure model is established for engineering experiment, see figure 1.

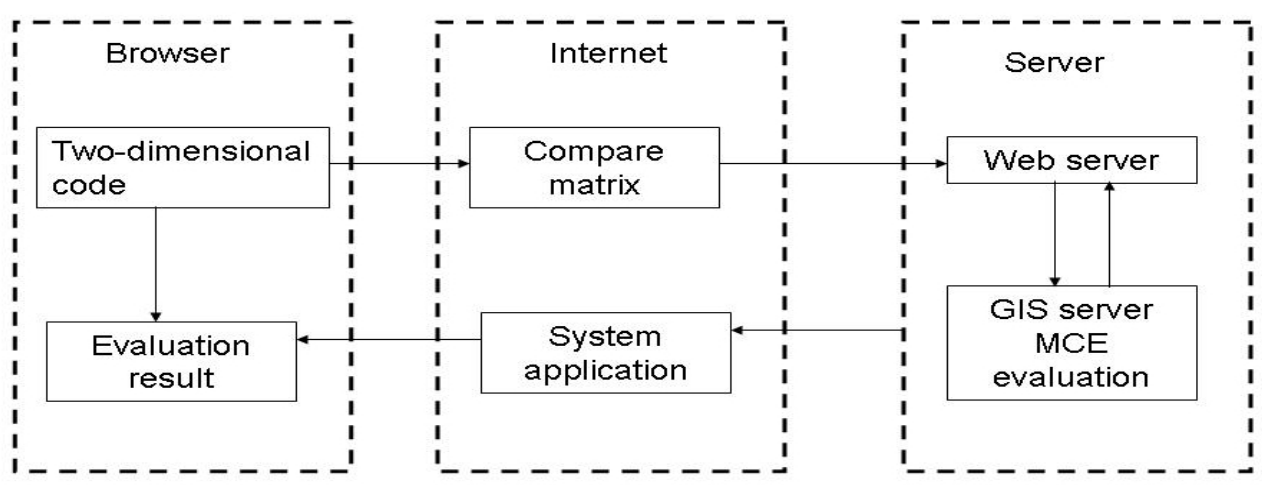

Figure 1. Browser/Server model for Engineering Experiment 
It is a three layers model, include browser for users as system application, server layer, and data transition layer. In sever layer, there are GIS server and web server, and many analysis can be achieved in this layer. Customers interact with GIS server through web server, and browse the experiment result through two-dimensional code. Many GIS analysis, such as surface analysis, decision making and safety evaluation, are achieved in the GIS server. ASP is a server side technology to create HTML page for users, and can be dynamic display in customer side. System application program are developed by VBScript and JavaScript language in ASP environment, also, the input parameters table and evaluation results are displayed to customer as asp web page.

\section{Application Example}

There are 120 oil wells in the research area, and the data is shown in table 1 . In this experiment, we will evaluate the casing failure risk based on 120 oil wells vapor injection data.

Table 1 Well data of vapor injection

\begin{tabular}{|l|c|c|c|l|c|c|c|}
\hline No. & $\begin{array}{c}\text { Amount of } \\
\text { vapour }\end{array}$ & $\begin{array}{c}\text { Injection } \\
\text { Number }\end{array}$ & $\begin{array}{c}\text { Injection } \\
\text { Pressure }\end{array}$ & No. & $\begin{array}{c}\text { Amount of } \\
\text { vapour }\end{array}$ & $\begin{array}{c}\text { Injection } \\
\text { Number }\end{array}$ & $\begin{array}{c}\text { Injection } \\
\text { Pressure }\end{array}$ \\
\hline $4-8$ & 14603 & 6 & 14.483 & $18-18$ & 67398 & 15 & 12.67333 \\
\hline $4-10$ & 5808 & 3 & 12.75 & $18-20$ & 46725 & 16 & 12.55625 \\
\hline $5-11$ & 31960 & 12 & 10.775 & $18-22$ & 44697 & 16 & 11.6062 \\
\hline $6-8$ & 9871 & 4 & 14.05 & $18-24$ & 44439 & 15 & 12.06 \\
\hline $6-10$ & 36989 & 14 & 11.9357 & $18-26$ & 58183 & 23 & 12.403 \\
\hline $6-12$ & 33810 & 11 & 10.87273 & $18-28$ & 26964 & 13 & 12.3153 \\
\hline $6-14$ & 40956 & 13 & 10.8076 & $18-30$ & 48521 & 20 & 12.91 \\
\hline $7-11$ & 21005 & 8 & 11.125 & $19-21$ & 61542 & 14 & 17.5142 \\
\hline $7-13$ & 32978 & 12 & 10.491 & $19-23$ & 36373 & 14 & 10.35 \\
\hline $8-10$ & 33495 & 12 & 11.55833 & $19-25$ & 19379 & 8 & 11.775 \\
\hline $8-14$ & 22888 & 7 & 11.8571 & $19-27$ & 28534 & 12 & 10.6083 \\
\hline $8-18 c$ & 43137 & 18 & 12.36111 & $20-18$ & 32871 & 11 & 13.4545 \\
\hline $9-11$ & 27736 & 10 & 11.24 & $20-20$ & 57579 & 19 & 11.28333 \\
\hline $9-13$ & 24082 & 9 & 11.07778 & $20-22$ & 44693 & 16 & 12.4375 \\
\hline $9-19$ & 18111 & 7 & 10.9857 & $20-24$ & 51608.7 & 19 & 12.1 \\
\hline $10-8$ & 7262 & 3 & 14.3666 & $20-26$ & 50818 & 20 & 11.485 \\
\hline $10-10$ & 35955 & 12 & 11.305 & $20-28$ & 14111 & 9 & 11.63333 \\
\hline $10-14$ & 43996 & 14 & 10.6285 & $20-30$ & 3244 & 1 & 11.4 \\
\hline $10-18$ & 5464 & 2 & 11.25 & $20-32$ & 5164 & 2 & 13.25 \\
\hline $10-20$ & 54059 & 18 & 12.08889 & $21-23$ & 48757 & 19 & 10.45556 \\
\hline $10-912$ & 5628 & 3 & 11.33333 & $21-25$ & 52788 & 20 & 10.018 \\
\hline $11-13$ & 22909 & 8 & 10.775 & $21-27$ & 25643 & 14 & 10.621 \\
\hline $11-15$ & 22185 & 10 & 11.13 & $21-29$ & 11808 & 5 & 11.84 \\
\hline $11-19$ & 32833 & 15 & 10.90667 & $22-20$ & 66217 & 24 & 11.165 \\
\hline $11-21$ & 39198 & 16 & 17.275 & $22-22$ & 65106 & 25 & 12.496 \\
\hline $12-12$ & 7201 & 3 & 10.7 & $22-24$ & 3286 & 1 & 15.2 \\
\hline $12-14$ & 14842 & 7 & 11.3 & $22-26$ & 52529 & 22 & 11.309 \\
\hline $12-16$ & 15139 & 6 & 12.66667 & $22-28 c$ & 12964 & 6 & 10.817 \\
\hline
\end{tabular}




\begin{tabular}{|c|c|c|c|c|c|c|c|}
\hline $12-18$ & 48157 & 18 & 11.4222 & $22-30$ & 53410 & 22 & 13.22 \\
\hline $12-20$ & 6941 & 2 & 11.25 & $22-32$ & 8473 & 4 & 12.35 \\
\hline $12-22$ & 47333 & 18 & 12.35 & $22-G 24$ & 49429 & 18 & 10.947 \\
\hline $13-13$ & 16139 & 8 & 11.7 & $23-25$ & 29132 & 12 & 11 \\
\hline $13-15$ & 14150 & 6 & 12.06667 & $23-27$ & 18304 & 11 & 11.236 \\
\hline $13-19$ & 38296 & 15 & 11.38667 & $24-24$ & 67009 & 29 & 12.025 \\
\hline $13-21$ & 36793 & 17 & 11.49333 & $24-26$ & 27695 & 13 & 11.675 \\
\hline $13-23$ & 47142 & 18 & 10.71667 & $24-28$ & 19661 & 7 & 11.5 \\
\hline $14-12$ & 20009 & 7 & 13.3 & $24-30$ & 4503 & 2 & 14.15 \\
\hline $14-14$ & 26886 & 10 & 12.87 & $24-32$ & 39844 & 17 & 14.859 \\
\hline $14-16$ & 9499 & 5 & 12.76 & $24-34$ & 5061 & 2 & 12.5 \\
\hline $14-18$ & 60406 & 20 & 12.02 & $24-36$ & 23540 & 10 & 12.39 \\
\hline $14-20$ & 39853 & 14 & 11.7857 & $25-27$ & 24239 & 11 & 13.409 \\
\hline $14-22$ & 45661 & 16 & 12.4812 & $26-24$ & 19634 & 9 & 11.9 \\
\hline $14-24$ & 18448 & 10 & 12.37 & $26-26$ & 57441 & 20 & 12.742 \\
\hline $15-19$ & 43295 & 16 & 11.12667 & $26-28$ & 40731 & 15 & 13.527 \\
\hline $15-21$ & 43681 & 17 & 10.6 & $26-30$ & 33617 & 14 & 15.35 \\
\hline $15-23$ & 42702 & 17 & 12.0705 & 26-32 & 3553 & 2 & 14.9 \\
\hline $15-25$ & 37020 & 15 & 11.55333 & $26-34$ & 36457.9 & 15 & 13.91333 \\
\hline $15-27$ & 10100 & 5 & 13.12 & $26-36$ & 5857 & 2 & 14.75 \\
\hline $16-16$ & 18301 & 7 & 11.9428 & $28-28$ & 53888 & 20 & 13.4 \\
\hline $16-18$ & 30489 & 10 & 11.12 & $28-30$ & 19763 & 10 & 16 \\
\hline $16-20$ & 23346 & 10 & 10.91 & $28-32$ & 55383 & 25 & 14.528 \\
\hline $16-22$ & 21915 & 8 & 11.575 & 28-34 & 21033 & 11 & 14.72 \\
\hline $16-24$ & 22070 & 8 & 11.7571 & $28-36$ & 43429 & 18 & 14.43 \\
\hline $16-26$ & 13457 & 7 & 12.2571 & $28-38$ & 11471 & 5 & 15.733 \\
\hline $16-28$ & 34017 & 11 & 12 & $30-28$ & 20126 & 9 & 15.644 \\
\hline $17-21$ & 41297 & 15 & 10.49333 & $30-30$ & 44696 & 18 & 14.7625 \\
\hline $17-23$ & 34794 & 15 & 11.1571 & $30-32$ & 29496 & 18 & 14.494 \\
\hline $17-25$ & 14418 & 5 & 10.66 & $30-34$ & 48001 & 16 & 15.12 \\
\hline $17-27$ & 22961 & 9 & 11.7111 & $32-26$ & 9598 & 9 & 17.525 \\
\hline $18-16$ & 26388 & 8 & 12.975 & $32-32$ & 19037 & 9 & 14.625 \\
\hline
\end{tabular}

The results of weights are $0.11,0.31,0.58$, and index of consistency is 0 . The evaluation result of this experiment is shown as figure 2. The two-dimensional codes are shown as figure3. 


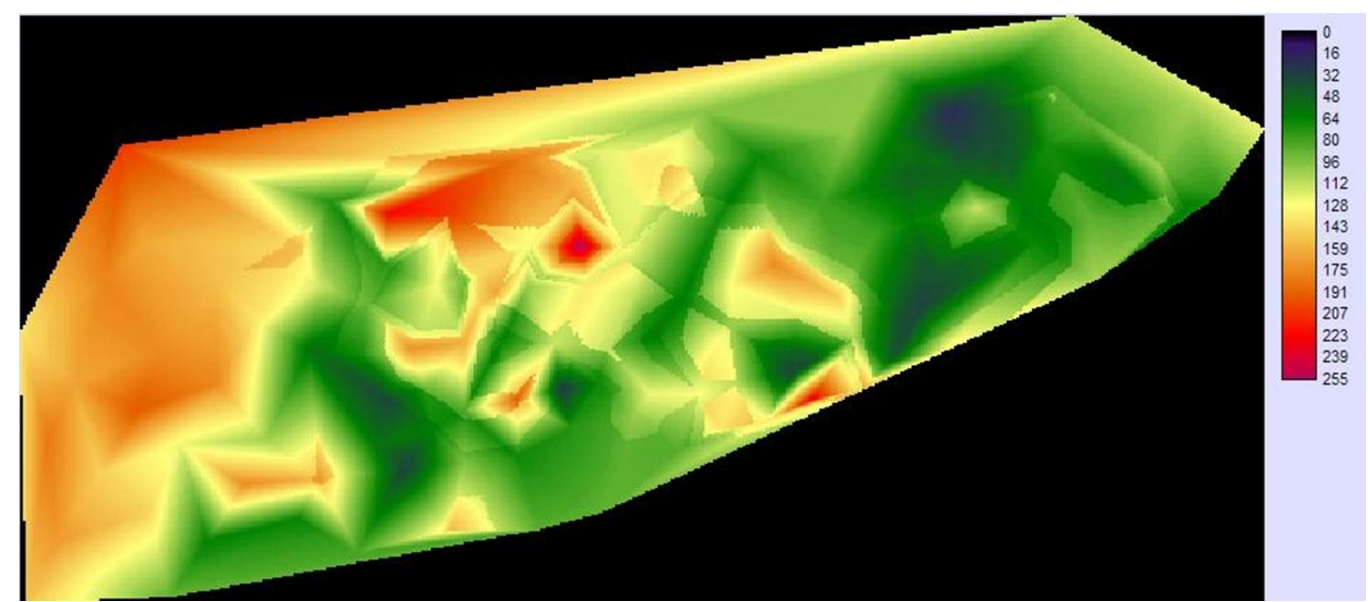

Figure 2. Experiment calculating result

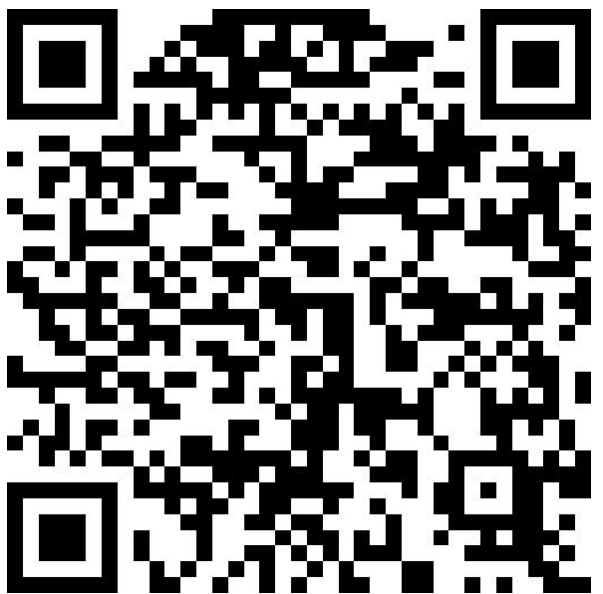

(a) Input data

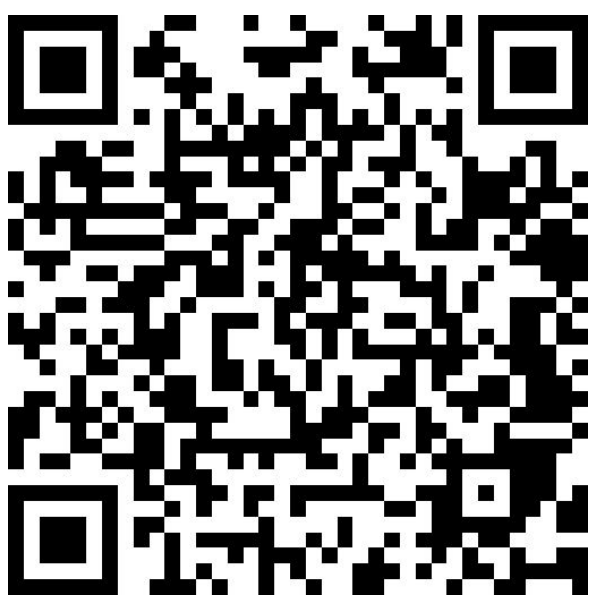

(b) Result access

Figure 3. Two-dimensional code

The two-dimensional codes is for data input and result browsing. Therefore, this engineering experiment can be fulfilled though mobile with two-dimensional code as basis of internet. Therefore, students can do the experiment through internet conveniently.

\section{Conclusions}

Through system structure design, an open experiment was developed for distance education, and students can fulfill engineering experiment with mobile with internet. MCE method is applied to evaluate the risk of casing failure as basis of 120 oil wells' data. In AHP method, the lack of consensus comes from the inconformity of comparison matrix. Therefore, to keep the conformity among factors in comparison matrix is the way to avoid error. The degree of consistency changes with the conformity among factors.

\section{Acknowledgements}

This work was financially supported by the Twelfth Five Year Plan Project of Education Science of Jiangsu Province (D/2013/01/130), and Research and Practice Project on the Reform of Postgraduate Education of Jiangsu Province (2015).

\section{References}

[1] R. Yin, L. Peng: Strategies of Knowledge Sharing in Web 2.0 Personal Learning Environment and Their Evaluation, Open Education Research, vol. 21(2), 2015, p.78-88. 
[2] J. Leng, X.J. Xu: Experiences and Trends of Educational Innovations Supported by Information Technology - An Interview with Prof. Christopher Dede, Open Education Research, vol. 20(4), 2014, p.4-8.

[3] A.J. Xie, Y.W. Tao, S.P. Luo, etal.: Construction of Practical Teaching System in Universities: Based on CDIO Engineering Education Concept, Journal of Changzhou University (Social Science Edition), vol.16(03), 2015, p. 118-121.

[4] J.F. Pei: Practice and Reflection on Integration for the Scientific Research and Teaching of Professional Courses, Journal of Changzhou University (Social Science Edition), vol.16(01), 2015, p. 111-115.

[5] G.S. Lan, Y.C. Zhang, L. Wang: Development of Educational Technology in the World: Knowledge Mapping and Visualization Analysis based on WOS and Histcite, Open Education Research, vol. 20(3), 2014, p.111-120.

[6] Q.J. Zhu, B. Hejmanowska: Analysis of GIS-based spatial variability and risk assessment, Journal of Chemical and Pharmaceutical Research, vol.5(9) ,2013, p.372-380.

[7] Z.J. Wang, L. Chen: Research on Instructional Interaction in Distance Education and its Latest Development, Open Education Research, vol. 21(2), 2015, p.30-39.

[8] T. Zhang, Q.J. Zhu, R. Ren, et al.: The Application of GIS-Based OWA Method in the Evaluation of Casing Damage of J25 Block, Journal of Changzhou University (Natural Science Edition), vol.27(03), 2015, p.51-55.

[9] S.h. Xu, N. Zhou, X.Y. Liu, etal.: Research of Chemical Industry Park Risk Management System Based on GIS, Journal of Changzhou University (Natural Science Edition), vol.24(04), 2012, p.73-77. [10]X. Li: Analysis on Reservoir Characteristics and Formation Mechanism of Low Permeability Reservoirs, Journal of Changzhou University (Natural Science Edition), vol.27(03), 2015, p.39-44.

[11]B. Liu, Y. Yang, S.L. Wang, etal.: Review on Corrosion and Protection of Pipeline in Casing, Journal of Changzhou University (Natural Science Edition), vol.27(04), 2015, p.59-62.

[12]B. Shi, S.L. Duan, Z.H. Ma, S.K. Xu, etal.: Design for System of Water Quality Evaluation in Fresh Water Ponds, Journal of Changzhou University (Natural Science Edition), vol.27(04), 2015, p.96-101. 